\title{
PLANO DE ENSINO DE ENFERMAGEM EM CENTRO CIRÚRGICO
}

\author{
Jeny Gibertoni * \\ Sonia Della Torre Salzano * \\ Brigitta Pfeiffer Castellanos - \\ Vanda Maria G. Jouclas * \\ Maria Belén Posso - \\ Ana Maria Marchetti *
}

GIBERTONI, J.; SALZANO, S.D.T.; CASTELLANOS, B.P.; JOUCLAS, V. G.M.; POSSO, M.B., MARCHETTI,A.M. - Plano de ensino de enfermagem em centro cirúrgico. Rev Esc. Enf. USP, 7(2): 152-176, 1973.

Todas as atividades realizadas no Centro Cinirgico tem como finalidade o paciente, justificando a inclusäo da disciplina Enfermagem em Centro Ciningico no Curriculo das Escolas de Enfermagem. Dado o reduzido tempo disponivel o programa é desenvolvido de maneira a enfatizar principios e dar experiências bäsicas que serāo aplicadas e suplementadas posteriormente. $O$ presente trabalho traz o plano de Ensino da disciplina e os roteiros utlizados pelos alunos.

\section{INTRODUÇÃO}

A disciplina Enfermagem em Centro Cirúrgico tem sido motivo de discuss Escolas de Enfermagem Algumas especialistas no planejamento desses Curriculos expressam a opiniăo de que o estágio em Centro Cirúrgico e um aglomerado de técnicas sem que a enfermeira tenha a oportunidade de prestar assistência de enfermagem ao paciente. Nos Estados Unidos da América do Norte o estágio em Centro Cirúrgico ficou limitado a simples observação, pe-

- Professor Assistente Doutor da disciplina Enfermagem em Centro Crúrgico.

- Auxiliar de Ensino da disciplina Enfermagem em Centro Cirúrgico. 
las alunas das atividades desenvolvidas ou foi abolido dos programas de muitas escolas de enfermagem. No entanto, temos refutado essas opiniōes com as seguintes asserçðes:

- o Levantamento de Recursos e Necessidades de Enfermagem da Associaçăo Brasileira de Enfermagem (1958) demonstrou que os enfermeiros estavam sendo requisitados principalmente para as chefias de Centros Cirúrgicos e Centros Obstétricos e Ginecológicos e que os demais setores não estavam exigindo a mesma atenção por parte dos responsáveis,

- dado o reduzido número de enfermeiros existentes e a urgência de sua contratação após a Graduação sem tempo de adquirir a necessária experiência, eles ficariam indubitavelmente responsáveis pelo Centro Cirúrgico se admitidos na Chefia do Serviço de Enfermagem de um Hospital;

- desde que o paciente entra para a Sala de Operaçóes até a sua volta para a Unidade de Enfermagem, o enfermeiro tem oportunidade de assistir física e psicologicamente o paciente;

- todas as atividades técnicas desenvolvidas no Centro Cinúrgico, incluindo o Centro de Material, tem como finalidade o paciente e a falta de observância de seus principios acarretarão a ele complicaçð̃es muitas vezes fatais.

Até recentemente a prática de campo em Enfermagem em Centro Cirúrgico desta escola tinha a duração de oito semanas; com a redução do semestre acadêmico para dezesseis semanas após a reforma universitária, essa prática foi limitada a quatro semanas o que nos levou a reformular o programa em termos de profundidade e flexibilidade e a selecionar melhor as experiências de campo para que o aluno tivesse realmente condiçðes de aprendizado.

Por ser muito especializada, a disciplina Enfermagem em Centro Cirúrgico acarreta para o aluno certa dificuldade inicial de adaptaçãa e requer do docente um ensino constante no campo.

Procuramos, por meio de um planejamento em equipe e avaliações constantes dos programas e experiências anteriores, elaborar um programa dinâmico, visando (no limitado tempo possível) oferecer ao aluno opor- 
tunidade de desempenhar atividades que permitam a aplicaçăo de conhecimentos cientificos e o desenvolvimento das habilidades necessárias para o desempenho eficiente de suas funçбes. Quando o ensino é bem motivado e há interesse por parte do aluno, o ensino se torna dinâmico e o aprendizado é o resultado natural. Para que isso seja possível, procuramos trabalhar num ambiente democrático onde há o maior respeito pela liberdade de cada um, lembrando sempre que liberdade não é licença, liberdade envolve responsabilidade (deveres e direitos). Franqueza disciplina autêntica e natural, compreensão e honestidade săo alicerces necessários para conseguir a manutenção desse ambiente.

0 que muito nos tem auxiliado, em termos de dinâmica na aprendizagem em Enfermagem em Centro Cirúrgico e o campo de ensino, pois existe um excelente entrosamento da Enfermagem com a equipe cirúrgica, facilitando a adaptação do aluno a essa unidade bastante complexa.

Sabemos que atualmente o aluno precisa aprender mais do que lhe é dado tempo no programa de graduação em Enfermagem, daí a importância cada vez maior de aproveitar ao máximo todas as oportunidades de aprendizado e canalizar seu interesse pessoal no sentido de aproveitar novas oportunidades por outro lado o docente está procurando a maneira de formar, no limitado tempo disponível, um enfermeiro com os conhecimentos basicos de que ele necessita e que serão suplementados com leitura bibliográfica e aplicados e desenvolvidos em experiências futuras..

Na reformulaçăo do ensino de Enfermagem em Centro Cirúrgico no seu conteúdo e forma, foi nossa preocupação constante fazer com que o aluno sinta a importância de qualquer tipo de atividade que desempenhe, pois ela e essencial para a segurança e o bem estar do paciente antes, durante e após a cirurgia 0 centro de interesse do enfermeiro em Sala de Operaçбes, bem como de todos os demais membros da equipe cirárgica é o paciente. $O$ objetivo fundamental da pratica de campo e o paciente como ser humano, membro de uma familia e de uma comunidade. Portanto a filosofia de trabatho do enfermeiro em Sala de Operaçбes baseia se diretamente no conceito que ele tem sobre o paciente Este ao chegar a Sala de Operaçбes não deve ser encarado como um simples nome da relação da lista de cirurgias, como se tivesse sido sempre paciente ou como se fosse ser paciente para todo o sempre. A afecção que o trouxe para o hospital, e mesmo o fator isolado cirurgia e anestesia, levam o indivíduo a um determinado grau de dependen- 
cia com relação à satisfação de suas necessidades básicas, nos três níveis de vida do homem psicobiológico, psicossocial e psicoespiritual. Cabe ao enfermeiro identificar essas necessidades básicas do indivíduo que precisam de atendimento e determinar o seu grau de dependência para que ele seja assistido em natureza e extensão. Para alcançar os objetivos propostos no programa elaborado, a experiência é desenvolvida em três níveis igualmente importantes:

- no cognitivo: onde o aluno aprende conceitos, generalizaçôes. e onde é ensinada a matéria;

- no psicomotor: que diz respeito às habilidades necessárias como um instrumento de trabalho e não como um fim;

- no afetivo: que se refere a atitudes, causas e modos de comportamento.

A avaliação deste ensino é efetuada de dois modos:

- exame das possibilidades do aluno, que lhe permitam condiçðes adequadas para seu aprendizado. Mais do que avaliar o aluno em termos de nota, nos importa a auto-avaliação diária de suas atividades e a avaliação feita pelo docente;

- análise do desenvolvimento do plano pedagógico, com finalidade de realizar os reajustes que se façam necessários ao preenchimento pleno de seus objetivos.

A avaliação do aluno é contínua, individual e não comparativa, pois cada estudante como pessoa humana, reage diferentemente a uma prática tão complexa como é a de Enfermagem em Centro Cirúrgico.

\section{PLANO DE ENSINO}

Código: ENC 326

Carga horária: 150 horas

Requisitos: Fundamentos de Enfermagem II créditos - aula: 6 créditos - trabalho: 2 
Número máximo de alunos em cada grupo: 15

\section{Objetivos gerais}

Ao término do ensino da disciplina o aluno deverá ser capaz de:

- planejar e prestar assistência física e psicológica aos pacientes na Sala de Operaçðes antes, durante e após a cirurgia e fazer as anotaçðes necessárias;

- planejar o trabalho, preparar a Sala de Operações e circular em cirurgia gastro-intestinal, das vias biliares, do pescoço e ginecológica, observando os aspectos éticos envolvidos;

- citar as fontes de contaminação da ferida operatória e em. pregar os meios existentes para evitá-las;

- descrever os métodos de hemostasia e os princípios físicos, empregados no funcionamento da unidade de eletrocirurgia e relacioná-los aos cuidados ao paciente durante a cirurgia;

- descrever e aplicar os princípios físico-químicos e microbiológicos nos processos de esterilização do material cirúrgico.

\section{Conteúdo do programa}

Introdução -7 horas

Objetivos:

- citar os princípios de ética estabelecidos em Centro Cirúrgico;

- citar os membros da equipe cirúrgica e suas funçð̄es;

- relacionar as atividades do Centro Cirúrgico com os serviços afins; 
- orientar o estudante quanto d̀s atividades a serem desenvolvidas e prepará-lo para a nova experiência.

\section{Conteúdo:}

- orientação ao programa e à prática de campo de Enfermagem em Centro Cirargico e o que se espera do estudante no decorrer dele; - ética na sala de operaçðes;

- noçðes em Centro Cirúrgico e Centro de Material no conjunto hospitalar;

- membros da equipe cirúrgica e suas funçōes;

- bibliografia.

Unidade I - Centro de Material: - 10 horas

Objetivos:

Ao término da Unidade o aluno deverá ser capaz de:

- descrever as áreas e seções de um Centro de Material centralizado e suas vantagens;

- aplicar os princípios racionais e cientificos no preparo e esterilização do material cirúrgico;

- descrever os princípios físico-químicos e microbiológicos empregados nos processos de destruição da bactéria;

- demonstrar o manuseio dos diversos aparelhos de esterilização e descrever seu funcionamento.

\section{Conteúdo:}

- noções de planta física do Centro de Material;

- preparo e acondicionamento do material cirúrgico;

- destruição dos microorganismos pelos meios físicos, quimicos e radiaç̃es;

- métodos biológicos usados para testar a esterilização do material cirúrgico. 
Unidade II - Funçбes da circulante na Sala de Operaç̋es: - 11 horas.

\section{Objetivos:}

Ao término da unidade o aluno deverá ser capaz de:

- enumerar os elementos básicos da planta física de um Centro Cirúrgico e o equipamento mínimo necessário;

- planejar e executar as funçбes do circulante em cirurgia gastro-intestinal, das vias biliares, ginecológica e do pescoço;

- citar os princípios de técnica assética utilizados em todas atividades na Sala de Operaçð̃es e no conjunto cirárgico;

- preparar a Sala de Operaçбes para a cirurgia;

- cuidar do material e da Sala de Operaçzes após a cirurgia;

- auxiliar os membros da equipe cirúrgica na execução de suas funçð̌es;

- enumerar os cuidados específicos com o material, e o paciente em cirurgias contaminadas;

- relacionar os cuidados ao paciente em Sala de Operaçðes com a assistência pré e pós-operatória;

- observar e anotar nos impressos próprios os dados pertinentes à cirurgia e ao paciente;

- planejar e executar a assistência física e psicológica aos pacientes na Sala de Operaçðes;

- citar os fatores que concorrem para a segurança do paciente na Sala de Operaçðes.

\section{Conteuido:}

- noçð̃es de planta física e equipamento mínimo da Sala de Operaçðes e elementos acessórios;

- preparo da Sala de Operaçðes para a cirurgia;

- técnica de sala contaminada;

- assistência de enfermagem ao paciente em Sala de Operaçðes antes, durante e após a cirurgia;

- anotaçðes. 
Unidade III - A Cirurgia: - 15 horas.

\section{Objetivos:}

Ao término da unidade o aluno deverá ser capaz de:

- citar os métodos de hemostasia;

- descrever os princípios de f́́sica empregados no funcionamento da unidade de eletrocirurgia e relacioná-los com os cuidados ao paciente durante a cirurgia;

- executar as técnicas de escovação, vestir avental e calçar luvas;

- esquematizar a disposição padrão dos grupos dos instrumentais cirúrgicos usados para uma cirurgia geral e reconhecê-los;

- descrever os tempos operatórios de um tipo de cirurgia geral relacionando os conhecimentos de anatomia e fisiologia com a cirurgia; - reconhecer as fontes de contaminação da ferida operatória e empregar os métodos existentes para evitá-las;

- definir as cirurgias mais comumente realizadas no Centro Cirúrgico do hospital usado como campo de prática.

\section{Conteúdo:}

- hemostasia: métodos usados e princípios aplicados ao funcionamento da unidade de eletrocirurgia;

- preparo da equipe cinúrgica para a cirurgia: princípios cientificos aplicados à técnica de escovação, de vestir avental e de calçar luvas;

- instrumental cirárgico básico: instrumentos comuns a todas as cirurgias e disposiçăo padrão dos instrumentos na mesa do instrumentador;

- atuação da circulante nas várias fases do ato cirúrgico;

- fontes de infecção da ferida operatória;

- assistência ao paciente anestésico-cirúrgico;

- nomenclatura cirúrgica.

Métodos de ensino:

- preleçðes com participação ativa dos alunos;

- demonstraçðes e ensino no campo; 
- seminários;

- discussðes em grupo;

- trabalho de campo;

- visitas;

- entrevistas individuais e em grupo;

- observação de Salas de Operaçðes de especialidades cirúr-

gicas;

- ensino clínico planejado e incidental.

Atividades discentes:

- prática de campo em Centro Cirúrgico (duas semanas) e em Centro de Material (uma semana); de (um a dois dias);

- estágio de observação em Sala de Operaç̃̃es de especialida-

- visitas de observação ao Centro Cirúrgico de um hospital de São Paulo (dois sub-grupos);

- relato, para o grupo e discussão da visita de observação;

- seminários (em número de três, cada um apresentado por um sub grupo), sobre:

- desinfecção e esterilização de materiais cirúrgicos por agentes químicos;

- fontes de infecção da ferida operatória;

- assistência de enfermagem ao paciente anestesiado.

- seminário sobre Estudo de um Paciente (três sub-grupos);

- relato semanal para o grupo e discussão de experiências no trabalho de campo;

- plano de trabalho (apresentado diariamente, por escrito) a partir da segunda semana;

- leitura programada;

- preenchimento diário de Folha de Atividades;

- preenchimento diário da Folha de Frequência.

Avaliação do rendimento escolar:

- boletim de avaliação referente à atuação do aluno no trabalho de campo;

- prova de aproveitamento;

- relatório das visitas efetuadas; 
- apresentação do estudo do paciente;

- participação do aluno nos seminários, nas discussões em grupo e nas pesquisas do departamento.

Material à disposiçāo do aluno:

- programa da disciplina;

- roteiros sobre:

- desinfeç̧ão e esterilização de material cirúrgico por agentes químicos (Anexo 1);

- fontes de infecção da ferida operatória (Anexo 2);

- assistência de enfermagem ao paciente anestesiado (Anexo 3);

- estudo de um paciente (Anexo 4);

- estágios de observação em Salas de Operaçðes especializadas (Anexo 5);

- estágios de observação em Centros Cirúrgicos de outros hospitais (Anexo 6);

- apostila sobre assistência de enfermagem ao paciente na Sala de Operaçōes (Anexo 7);

- folha de avaliação diária (Anexo 8);

- bibliografia (Anexo 9). 


\section{ANEXO 1}

Roteiro para seminánio sobre: desinfeç̧ão e esterilização de materiais cirnirgicos por agentes químicos.

- Consulta bibliográfica sobre características, porcentagem, uso e cuidados em relação a esses agentes.

- Levantamento dos agentes químicos utilizados no Hospital das Clínicas, Hospital Nove de Julho e Santa Casa de Misericórdia de São Paulo com as respectivas concentraçðes e usos.

- Análise comparativa entre as informaçסes encontradas na literatura e nos hospitais visitados.

- Conclusões.

Bibliografia espectfica

- Material bibliográfico obtido pelos próprios alunos em laboratórios (Darrow, Johnson, Winthrop, etc.) ou alhures.

\section{ANEXO 2}

Roteiro para o seminário: FONTES DE INFECÇÃO DA FERIDA OPERATORIA.

- Fontes de infecção.

- Paciente.

- Pessoal.

- Ambiente.

- Material cirúrgico.

- Vef́culo usado para transporte do paciente.

- Medidas para controle de infecção em hospitais

- Conclusð̄es e recomendaçðes.

- Bibliografia e outras fontes consultadas. 


\begin{abstract}
ANEXO 3
Roteiro para apresentação do semináno sobre ASSISTENCIA DE ENFERMAGEM AO PACIENTE ANESTESIADO.

Assistência de enfermagem ao paciente nas anestesias: geral, raqueanas, sub-aracnóide e peridural e local.

- Conceituar os tipos de anestesia e, no caso de anestesia geral, descrever as fases da anestesia, relacionando as drogas comumente usadas em cada fase com as vias de administração.

- Citar o material necessário e o equipamento, se for o caso, relacionando-o com o seu uso.

- Descrever as drogas utilizadas e o seu uso.

- Descrever o preparo do doente para a anestesia.

após a anestesia.

- Enumerar os cuidados com o paciente antes, durante e

- Relacionar as possíveis complicaçð̃es

- Bibliografia e outras fontes consultadas.
\end{abstract}

ANEXO 4

Roteiro para seminário sobre ESTUDO DE UM PACIENTE.

- O paciente como individuo e membro da Comunidade Identificação, percep̧̧ão e expectativas sobre sua doença e a cirurgia e ajustamento ao Hospital.

- Dados de interesse para a Enfermagem - Estudo descritivo da afecção e sua sintomatologia. Etiologia. Sintomatologia Individual. Exames para diagnóstico e responsabilidade da enfermeira quanto aos cuidados necessários. Resultado e avaliação dos exames. Operação proposta para a correção cirúrgica. Operação realizada. Material e instrumental especiais utilizados na cirurgia. Tipo de anestesia utilizada.

- Assistência de Enfermagem - Evolução dos cuidados de enfermagem no atendimento às necessidades básicas do paciente afetadas: 
- no período pré-operatório;

- durante a cirurgia, desde a entrada no centro Cirúrgico até a salda;

- no poss-operatório imediato;

- no pós-operatório mediato.

- Conclusão.

- Bibliografia e outras fontes consultadas.

\title{
ANEXO 5
}

Roteiro para o estágio de Observação em Salas de Operaçōes especializadas.

- Planta física (descrição sumária). Avaliação.

- Equipamento - disposição funcional.

- Apare thos especializados.

- Material especializado (na cirurgia observada).

- Funçбes da circulante:

- técnica da montagem da Sala de Operações;

- técnica asséptica;

- atitude;

- condiçðes de trabalho.

- Sugestðes.

\begin{abstract}
ANEXO 6
Roteiro para o estágio de observação em Centros Cirurgicos de outros hospitais.

Hospital

- Nome

- Tipo de hospital (geral, especializado, misto).

- Número de leitos.

- Número de leitos cirúrgicos.

- Entidade mantenedora (particular, previdenciária, assisten-
\end{abstract} cial). 
- Namero de operaçðes diárias.

Centro Cinírgico

- Localização: interna em relação às clínicas e serviços do hospital e externa em relação ao tráfego.

- Planta física - esquema.

- Fluxograma.

- Tipos de cirurgia.

- Entrosamento com serviços afins.

- Regimento do Centro Cirúrgico (se existe ou não).

- Rotinas de funcionamento (se existe ou não).

- Controle de material (impressos).

- Equipe de enfermagem - número, tipo e funçðes.

- Condiçðes do ambiente de trabalho.

- Controle de infecçðes: tipo e frequência.

- Horário de funcionamento.

- Uso de uniforme privativo.

Salas de Operações

- Localização.

- Número e tipo.

- Forma e tamanho.

- Detalhes de construção: paredes, cantos, piso, cor, portas, janelas. tomadas elétricas, iluminação natural e artificial, ventilação, forro, etc..

- Equipamento das Salas de Operaçðes: fixo e permanente.

- Preparo da sala para a cirurgia.

- Suturas usadas - esterilização da parte externa e técnica no manuseio.

- Material e método de antissepsia de mãos e antebraços da equipe cirargica.

- Localização da seç̧ão de reserva de material esterilizado.

- Manuseio e destino de roupas e material sujo.

- Instalaçðes centralizadas.

- Cuidados de enfermagem ao paciente.

- Técnica da sala contaminada.

Elementos acessórios

Localização, características e equipamento de: 
- lavabos;

- ante-salas;

- sala de admissão de pacientes;

- sala de anestesia;

- sala de supervisora de enfermagem;

- sala de reserva de material para limpeza;

- sala de café;

- vestiário e sanitário;

- centro de recuperação pós-anestésica - sobre este mencio--

nar ainda:

- número de leitos

- tempo de permanência do paciente

- aparelhos especiais

- cuidados de enfermagem ministrados

- impressos

\section{Centro de Material}

- Centralização.

- Planta física - esquema.

- Fluxograma.

- Esterilização de material:

- métodos de esterilização: físicos, químicos e radiaçðes.

- material e método usados para desinfecção química e sua finalidade.

- controle de esterilidade: método usado e frequência.

- Áreas:

- de preparo: limpeza, preparo e acondicionamento;

- de esterilização;

- de reserva: localização de material limpo e esterilizado.

- Recebimento de material sujo ou limpo e entrega de material esterilizado.

- Condiçðes do ambiente de trabalho.

- Entrosamento com serviços afins (banco de sangue, farmácia, almoxarifado, lavanderia, raios X, laboratório, anestesia).

- Controle de material - impressos.

- Regimento do Centro de Material.

- Rotinas de funcionamento.

- Número de pessoas, tipo e funções. 
Pesquisas realizadas pela equipe do Centro Cirnirgico e Centro de Material.

Avaliação e conclusōes.

Bibliografia e outras fontes consultadas.

\begin{abstract}
ANEXO 7
Assistência de Enfermagem ao paciente na Sala de Operações.

- Conhecer o paciente na véspera.

- Recebêlo cordialmente no local designado até sua ida para a Sala de Operaçð̌es.
\end{abstract}

- Dispensar-lhe atenção e procurar tranquilizá-lo se necessánio.

- Verificar prescrição e aplicação da medicação pré-anestésica.

- Observar condiçбes físicas: sinais de resfriado, processos alérgicos, etc..

- Observar a tricotomia.

- Observar proteção de cabelos.

- Verificar a existência de próteses e adornos.

- Checar na papeleta: jejum, lavagem intestinal, sinais vitais, esvaziamento da bexiga, etc..

- Abrir sondas e catéteres.

- Acompanhar o paciente até a Sala de Operaçōes.

- Auxiliá-lo a passar para a mesa operatória.

- Verificar com o anestesista quais os materiais e as medicaçð̃es necessárias para a anestesia e aspiração, providenciando o que faltar. - Auxiliar o anestesista na conexão de intermediários do aparelho de anestesia e infusão de líquidos (soro, sangue), bem como na aspiração de secreçðes.

- Estar ao lado do paciente na hora da induçāo anestésica ; para que ele não se sinta só.

- Observar o paciente e suas condiçðes gerais durante a anestesia e o decorrer da cirurgia, providenciando material suplementar se necessário. 
- Identificar cuidadosamente o sangue usado para transfusão.

- Ficar junto ao paciente no despertar da anestesia para lhe dar apoio.

- Auxiliar na passagem do paciente da mesa operatória para a mesa.

- Identificar espécimes se houver.

- Enviar papeleta, prontuário, espécimens, ficha de requisisição de exame anátomo-patológico e de anestesia junto com o paciente.

- Encaminhar para a secção competente o material usado pelo anestesista. 


\section{ANEXO 8}

Folha de Avaliação Diária

Nome do Aluno

Ano.

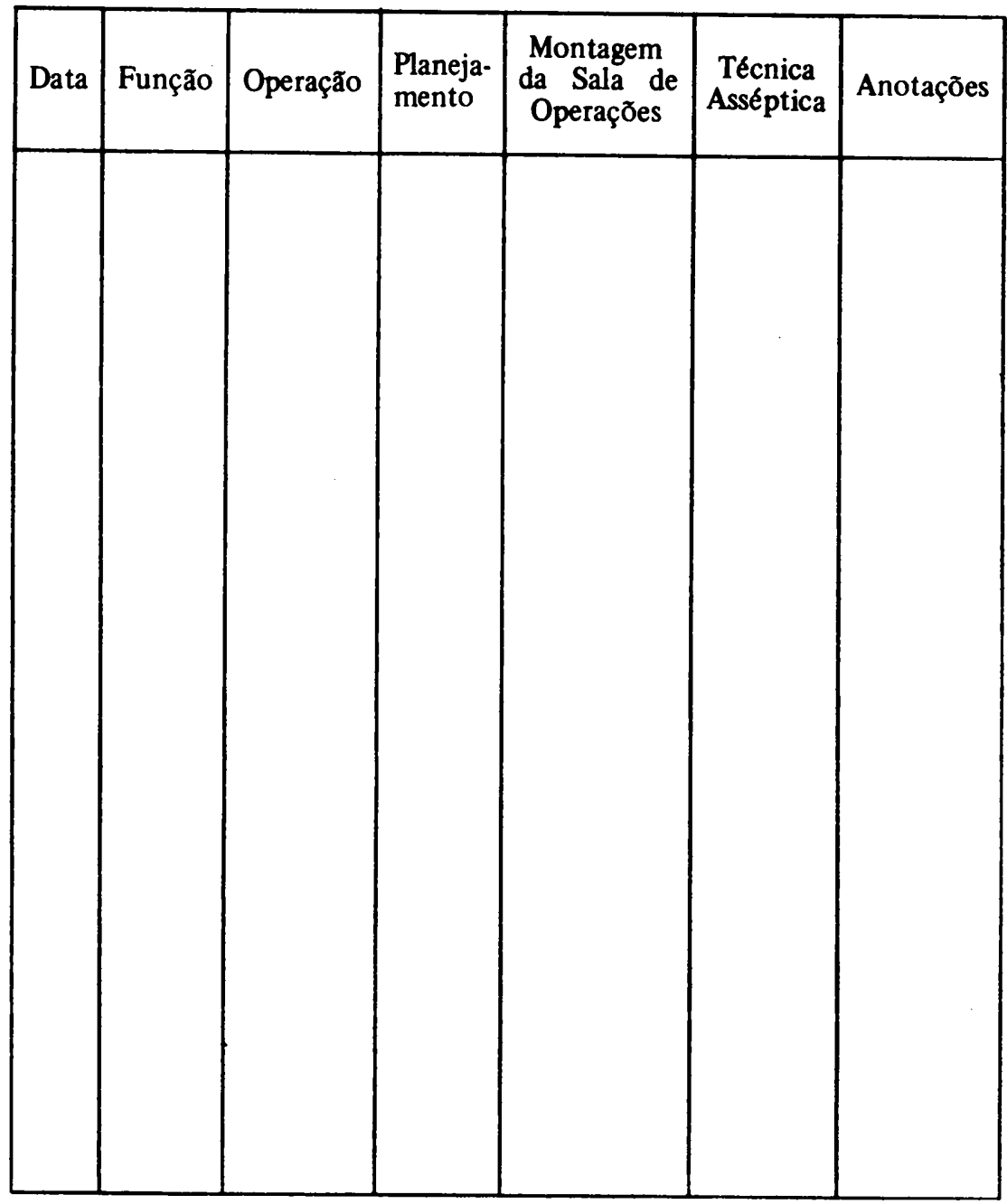


$170-$

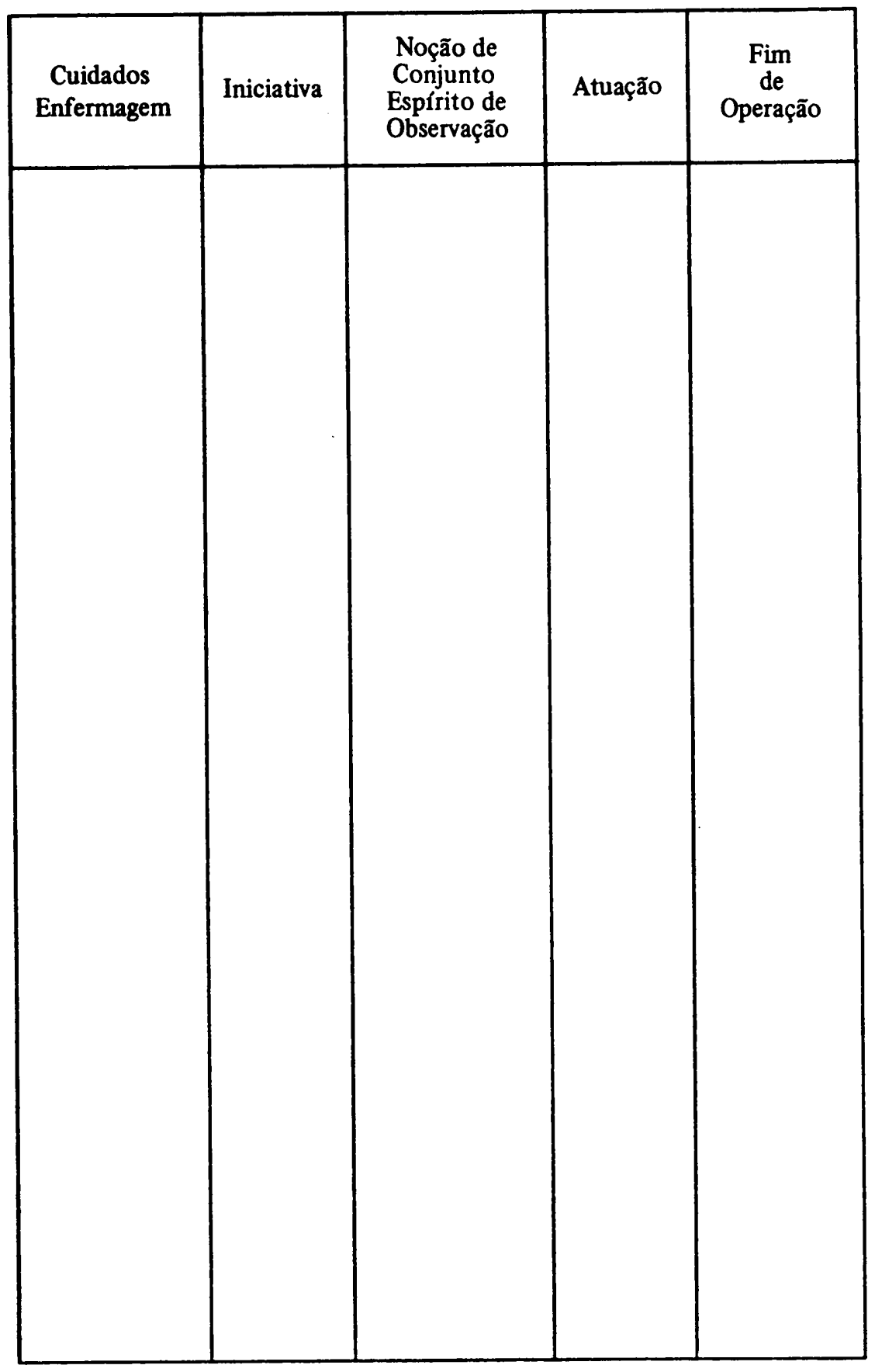




\section{ANEXO 9}

\section{Bibliografia}

Livros

BALLINGER, W. F. et al. - Alexander's care of the patient in surgery. 5th. ed. Saint Louis, Mosby, 1972.

ECKERT, C. - Emergeney - roon care. 2nd es. Boston Little Brown, 1971.

GINSBERG, F. et al. - A manual of operating roon technology. Philadelphia, Lippincott, 1966.

GOMES, A. - Técnica de Quirófano. México, Interamericana, 1967.

HEGEMANN, G. - Técnica operatória general. Montivideo, Labor, 1965.

KIRSCHNER, G. - Tratado de técnica operatória general y especial Barcelona, Labor, 1965.

LE MAITRE, G. \& FINNEGAN, J. - The patient in sungery. 2nd. ed. Philadelphia, W. B. Saunders, 1970.

MELLO, J. - Simposios de cinurgia. São Paulo, Carlo Erba, 1966.

MILLER, R. F. - O triunfo sobre a dor. Rio de Janeiro, José Olympio, /s.d./. PERKINS, J. - Principles and methods of esterilization in health sciences 2nd. ed. Springfield, Illinois, Charles C. Thomas, 1969.

PINOTTI, H. W., org. - Atualização cinirgica. São Paulo, Johnson \& Johnson, 1960/1971. 4v.

SEEDOR, M. - Introduction to assepsis. New York, Columbia University Press, 1964.

SPADAFORA, A. - Las manobras quinungicas. Buenos Aires, Editorial Bibliográfica Argentina, 1969.

STANIER, DOUDOROFF, ADELBER - Mundo dos micróbios. São Paulo, Blucher, 1969.

THORWALD, J. - O século dos cirurgiōes. São Paulo, Boa Leitura, /s.d./

Periódicos

ABRAM, H. - Psycological problems of patients after open-heart surgery. Hosp. Topics, 44 (1): 111-3, jan. 1966.

ALVIN, F. - A enfermagem na eletrocirurgia. Rev. paul Hosp., 15 
(12): 46-69, dez. 1967.

AMADO, G. - A Enfermagem Moderna. Rev. paul. Hosp., 17 (3): 8-13 mar. 1969.

AMADO, G. - 0 respeito à pessoa do paciente. Rev. paul. Hosp., 14 (9): 22-3, set. 1966.

BASTOS, M. - A Enfermeira Anestesista. Rev. paul. Hosp., 14 (5): 48-9, 1966.

BATTING, C. G. - Eletrosurgical burn injuries and their prevention. JAMA, 204 (12): 91-5, 1968.

BEDOYA, A. - Centro quirurgico centralizado e descentralizado. Rev. paul Hosp., 14 (3): 40-5, 1966.

BERNARD, H. - Recirculation of air in the surgical suite. Hospital, 35 (21): 46, nov. 1961.

BERNARD, S. - Report on six month's experience with a nonporous surgical drape. Hosp. Topics, 47 (6): 109-10, jun. 1969.

BLUMBERG, M. S. - Hospitals borrow industrial clean rooms. Mod. Hosp., 101 (1): 10, jul. 1964.

BRAGALIA, P. - 0 problema do abôrto e o segrêdo profissional. Rev. paul. Hosp., 15 (2): 5-9, fev. 1967.

BULLER, S. - Medidas de profilaxia para evitar a contaminação do catgut pelo Chlostridium tetani e outros germes patogênicos. Hosp. de Hoje, 18: 1-4, 1963.

CARVALHO, L. - As infeç̧ð̃es estafilocócicas no Hospital. Rev. paul Hosp., 11 (12): 23-7, 1964.

CARVAlHO, L. - Controle de infeç̧̋es no Hospital. Rev. paul. Hosp., 11 (4): 18-24, 1964.

CARVALHO, L. - Infecç̋̃es no centro cirúrgico e no berçário. Rev. paul. Hosp., 15 (3): 10-4, 1967.

CARVALHO, S. - Comentários médico-legais sobre o problema dos transplantes de tecidos e de órgãos de doadores vivos e oriundos de cadíveres. Hosp. de Hoje, 34: 3-6, 1968.

CORREA, P. C. - Assepsia nas salas de cirurgia. Rev. paul Hosp., 11 (5): 40, 1964.

CORTES, G. - Infecçðes vehiculadas por el aire y su control en el hospital Re poul. Hosp., 9 (12): 24-38, 1961.

COUTO, L. - Centro de material esterilizado para um hospital geral de 200 leitos. Rev. poul. Hosp., 15 (7): 12-26, 1967.

CRISTOVÃO, D. - Contágio através do ar. Hosp. de Hoje, 15: 37, 61. 
CRONE, J. - Disposal system fights fire end infection. Mod. Hosp. 101 (6): $132-4$, dec. 1963.

DAHER, S. - Infeç̧ões pós operatórias, como evitá-las. Rev. paul. Hosp., 15 (2): 11-9, 1967.

DANTAS, P. S. - Métodos de esterilização. Rev. paul Hosp., 9 (2): 27-30, 1961.

FERRARINI e CHIARELLO - Centro de Tratamentos intensivos e Centro de Recuperação. Rev. paul. Hosp., 11 (12): 37-9, dez. 1963.

GARÓFALO, F. - O material hospitalar: necessidade de padronização na economia do hospital. Rev. paul. Hosp., 9 (9): 31-3, 1961.

GERMECK, O. - Esterilização pelo calor sêco. Hosp. de Hoje, 16 314, 1962.

GIBERTONI, J. - Assistência psicológica ao paciente para a cirurgia. Rev. Bras. Enfermagem, 20 (4): 237-289, ago. 1967.

GINSBERG, F. - How to process surgical tissue specimens. Mod. Hosp., 99: 104, 1962.

GINSBERG, F. - Regular bacteriology testing program necessary for quality care. Mod. Hosp., 109 (1): 114, jul. 1967.

GUAZZELLI, F. - Aire acondicionado en el centro quirurgico. Rev. paul. Hosp., 15 (7): 52-60, 1967.

GUIMARÃES, C. - Contaminação na sala operatória. Medicina Hospitalar, 1 (5): 8-13, jan. 1968.

GUIMARÃES, E. - Equipamento do centro de material de um hospital de 100 leitos. Rev. paul. Hosp., 11 (5): 27-31, 1963.

HUGHES, R. B. - Children's fear of surgery. Hosp. Topics, 45 (9): 116-7, sep. 1967.

JORGENSEN, B. I. - Maintenance of suction equipment. Hosp. Topics 46 (11): 81-2, nov. 1968.

KESSLER, R. E., et al. - Filtration of shistosomes inanesthetized man $J A$ $M A, 214$ (3): 519-24, 1970.

LA TORRE, L. A. de - Centro Cirúrgico - Perigo de Explosø̃es. Rev. paul Hosp., 9 (3): 48-9, mar. 1961.

LANG, G. - Centro de Recuperação pós-operatório. Rev. poull Hosp., 8, (4): 20-1, abr. 1960.

LARSEN, M. - Assepsia do centro cirúrgico. Rev. paul Hosp., 9 (7): 12-26, 1961.

LEITE, O. - Ética médica e Hospitalar. Rev. paul. Hosp., 18 (7): 5-9, jul. 1970.

LIMA, C. - Métodos físicos de desinfeç̧ão e esterilização. Hosp. de Hoje, 16: 29-30, 1962. 
MIRANDA, C. - Sistema central de vácuo proporciona rapidez e economia. Med. Hosp., 1 (6): 33, fev. 1968.

MORAES, I. - Padrões mínimos paraccentro de recuperação. Rev. paul Hosp., 11 (4): 13-5, abr. 1963.

MULLER E ST APE - Contribuição da Enfermagem na recuperação do paciente. Rev. paul Hosp., 16 (6): 18-27, jun. 1968.

NAVES, Z. - Centro cirúrgico e obstétrico num hospital de cirurgia de 100 leitos. Rev. paul. Hosp., 15 (5): 40-52, 1967.

NEGRO, R. - A importância do uniforme no centro cirúrgico. Rev. paul. Hosp., 13 (2): 28-32, fev. 1965.

PEDROSO, O. - Centro cirúrgico: centro de material. Rev. paul. Hosp., 8 (7): 20-3, 1960.

PEDROSO, O. - Influência da cirurgia na elevação do padrão hospitalar. Rev. paul. Hosp., 11 (10): 27-9, out. 1963.

PORTEllaDA, P. C. L. - Infeç̧ão. Hosp. de Hoje, 24: 17-9, 1965. - Aspectos atuais da fisiologia da esporogênese em aeróbios. Hosp. de Hoje, 22: 23-4: 1964.

PREITCHINIS, J. - Psychological care of patient important to surgery's outcome. Hosp. Topics. 43 (11): 113-9, nov. 1965.

RICHTER, E. - Enfermagem em centro cirúrgico. Rev. paul. Hosp., 8 (1): 18-33, jan. 1960.

RICHTER, E. - O paciente como centro na sala de operações. Rev. paul. Hosp., 9 (4): 20, abr. 1961.

RICHTER, E. - Preparo e esterilização de roupas e dobraduras. Hosp. de Hoje, 19: 9-14, 1963.

SALZANO, S. - Cuidados de Enfermagem ao paciente anestesiado. Rev. Esc. Enf. U.S.P., 2 (1): 81.92, mar. 1968.

SALZANO, S. - Estudo da ação do parafórmico nas bactérias em forma esporulada. Rev. Esc. Enf. U.S.P., 2 (2): 46-57, set. 1968.

SANCHES, S. - O comando no centro de material esterilizado. Rev. paul. Hosp., 13 (8): 39-45, 1965.

SAPP, E. - The O.R. nurses wear pants as an aid in infection control. Hosp. Topics, 44 (7): 121-2, 1966.

SILVA, M. - Planejamento e equipamento de um centro de material esterilizado para um hospital de 500 leitos. Rev. paul. Hosp., 15 (2): 20-3, 1967.

SMITH, H. - O emprego dos desinfetantes no hospital. Rev. paul. Hosp., 14 (11): 30-4, 1966.

SONNELAND, J. - Does operating room modernization affects the incidence 
of infection? Hosp. Topics, 44 (6): 149-50, 1966.

TALAVERA, J. - La iluminacion en la sala de operaciones. Rev. paul. Hosp., 14 (4): 7.33, 1966.

UM CORAÇÃo parou, mas outros baterão. Atualidades Médicas, 3 (10): 30-1, jan. 1968.

WALD, A. S. et al. - Accidental burns associated with oletrocautery. JAMA, 217 (7): 916-21, 1967.

WALTER, C. - Drenagem de abcesso com cultura positiva para Staphylococcus. Hosp. Topics, 40 (12): 90, 1962.

ZERBINI, E. J. - Padronização da técnica de transplante de coração. Medicina Hospitalar, 1 (6): 9, 1968.

Teses

GIBERTONI, J. - Avaliação de um método de antissepsia da pele de mãose antebraços de equipes cińrgicas com composto quaternário de amonio, sem uso prévio de escova e sabão. São Paulo, 1972. (Tese - Escola de Enfermagem da USP).

HUTZLER, R. U. - Staphylococcus aureus e bactérias gram negativas em pacientes hospitalizados. São Paulo, 1971. (Tese - Faculdade de Medicina da USP).

MARCHESOTTI, E. - Contribuição para o estudo da colonização bacteriana aeróbica patogenica da pele e infeç̧ão pós operatória da parede abdominal. São Paulo, 1972. (Tese - Escola de Enfermagem da USP).

SALZANO, S. - Estudo da variação de temperatura córperea no paciente anestésico-cinirgico. São Paulo, 1972. (Tese - Escola de Enfermagem da USP). 
GIBERTONI, J.; SALZANO, S.D.T.; CASTELLANOS, B.P.; JOUCLAS, V.M.; POSSO, M.B.; MARCHETTI, A.M. - Teaching program of operating room nursing. Rev. Esc. Enf. USP, 7(2): 152-176, 1973.

All activities performed in the Operating Room are patient centered. This fact justifies the inclusion of the subject Operating Room Nursing in the basic curriculum. Because of the short time available, to this subject, at this school (4 weeks), the program is developed so as to emphasize principles and to provide basic experiences which will be further suplemented by the students. This work presents the teaching plan and the guides used by the students. 